\title{
Analysis of Special Consequences and Losses of Equipment Accident in Thermal Power Plant
}

\author{
Shuai Kong ${ }^{1,2}$, Xuefen $\mathrm{Yu}^{1,2^{*}}$, Zhangwei Ling ${ }^{1,2}$, Ping Tang ${ }^{1,2}$ and Nanhui Jin ${ }^{1,2}$ \\ ${ }^{1}$ Zhejiang Academy of Special Equipment Science, Hangzhou, 310020, China \\ ${ }^{2}$ Key Laboratory of Special Equipment Safety Testing Technology of Zhejiang Province, Hangzhou, 310020, China
}

\begin{abstract}
Many types of equipment in the thermal power plant has special risks. Once a safety accident occurs, it often causes special consequences and losses. The indirect losses are difficult to calculate in general due to the special property. In this paper, a calculation model was proposed, considering collateral production impact on upstream and downstream industries, the inconvenience impact on people's electricity and gas supply, and social security panic by rapidly spreading to media and public opinion. An example of a main steam pipe burst accident in a thermal power plant was analysed. The ratio of indirect economic losses and direct economic losses was obtained. Results showed that the ratio value (35.4) was much higher than the value (4) of general industrial accident loss. The ratio value maybe even much higher if the internal medium of special equipment has strong toxic and harmful effects. It is quite important to make concerted efforts to manufacture, usage, management, inspection, safety monitoring, and scientific supervision, in order to detect and eliminate hidden dangers early and ensure the safe operation of special equipment.
\end{abstract}

\section{Introduction}

Many types of equipment in thermal power plants, such as the boiler and the pipe, are defined as "Special Equipment" in China. Special equipment has "Special" risks. Once a safety accident occurs, it often causes special consequences and losses. The losses not only include severe direct losses but also include big indirect losses. The indirect losses are difficult to calculate in general due to the "Special" property. The "Special" losses may include collateral production impact on upstream and downstream industries, may include the inconvenience impact to people's electricity and gas supply, may include social security panic by rapidly spreading to media and public opinion. In order to analyse the special consequences and losses of equipment accidents in the thermal power plant, a calculation model was proposed, and an example was analysed in this paper. The ratio of indirect economic losses and direct economic losses was obtained.

\section{General method of accident loss calculation}

The international research on accident losses has experienced about one century. Mainly 4 stages can be divided, including Heinrich (1930), Simonds (1956), Andreoni (1986), and HSE (British Health and Safety Executive, 1994). [1] Each stage has further development on the basis of the previous stage. W. H. Heinrich defined
11 types as indirect losses and obtained the ratio of indirect economic losses and direct economic losses was 4:1 through statistic. [2] R. H. Simonds defined 10 different types as indirect losses and proposed an average method instead of using a 4:1 ratio to calculate overall losses. [3] D. Andreoni considered that the loss was composed of costs in the production planning stage, costs during the operation of the enterprise, and financial losses associated with production losses. [4] HSE considered that the ratio of indirect economic losses and direct economic losses varied by researchers, and it was better to use the ratio of insurance fees and non-insurance fees. [5]

\section{Special equipment accident loss calculation model}

Based on previous methods and standard specifications [6], a calculation model was provided to determine the special equipment accident loss. The overall loss (L) was composed of 4 parts: accident direct economic loss (A), accident indirect economic loss (B), accident direct noneconomic loss (C), accident indirect non-economic loss (D). Equation (1) was obtained directly.

$$
L=A+B+C+D
$$

When establishing the composition of $\mathrm{ABCD}$, the special attributes of special equipment were considered, including collateral production impact on upstream and downstream industries, the inconvenience impact to people's electricity and gas supply, and social security panic by rapidly spreading to media and public opinion, as

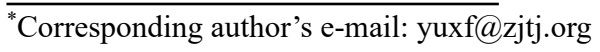


seen in Figure 1.

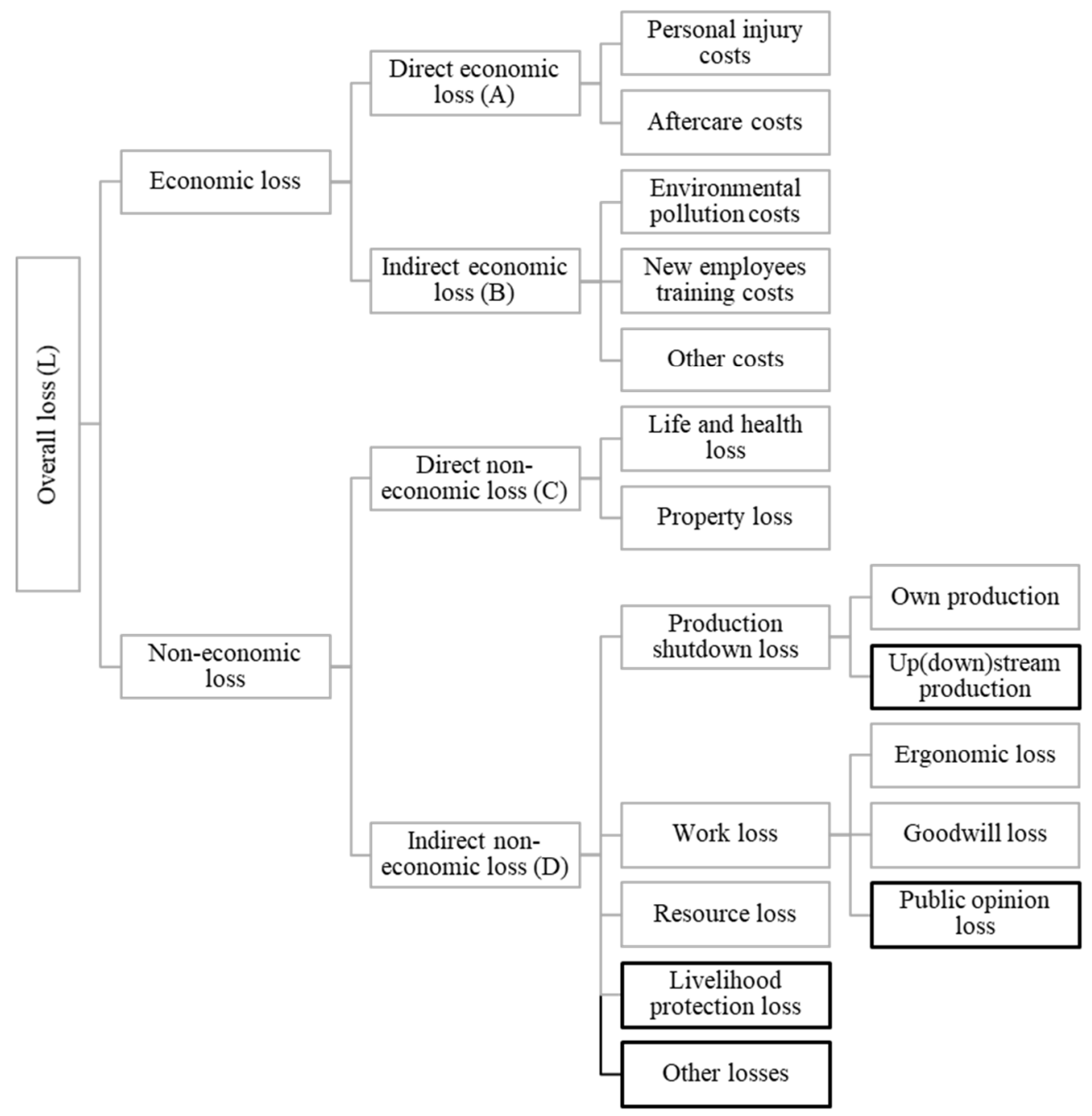

Figure 1. Special equipment accident loss calculation model structure

\section{Example and Results}

A main steam pipe burst in a thermal power plant. The accident direct economic loss was about 19 million determined by accident investigation. The indirect losses were considered as below.

\subsection{Product sales discount loss}

The equipment was put back into operation after a repair, but the customer has doubts about the stable supply of the plant. Both sides reached an agreement of an $8 \%\left(\eta_{\mathrm{dc}}\right)$ discount on the sale price for 300 days. According to the calculation of plant, the discount account $M_{\mathrm{dc}}$ was about 12 million.

\subsection{Production shutdown loss}

As the accident pipe was newly built, the operating time was less than one year before the accident. The annual sale $\left(M_{\mathrm{an}}\right)$ was estimated by:

$$
M_{\mathrm{an}}=M_{\mathrm{d}} \times \frac{1}{\eta_{\mathrm{dc}}} \times \frac{365}{D_{\mathrm{dc}}}=182.5 \text { million }
$$

The shutdown repair time $\left(D_{\mathrm{sd}}\right)$ was 73 days, so the production shutdown loss was:

$$
M_{\mathrm{sd}}=M_{\mathrm{an}} \times \frac{D_{\mathrm{sd}}}{365}=36.5 \text { million }
$$

\subsection{Work loss}

According to the calculation of plant, the tax and profit loss during production shutdown $\left(S L_{\mathrm{sd}}\right)$ was about 3 million, so annual tax $\left(S L_{\mathrm{an}}\right)$ and profit can be estimated by:

$$
S L_{\text {an }}=\frac{365}{D_{\text {sd }}}=15 \text { million }
$$

There were 51 employees in the production department, and the annual working day was calculated as 250 days. There were 6 people died and 3 seriously injured in the accident, so the work loss was estimated by:

$$
M_{\mathrm{wk}}=(6000 \times 6+3000 \times 3) \times\left(\frac{S L_{\mathrm{an}}}{51 \times 250}\right)=
$$$$
52.9 \text { million(5) }
$$ 


\subsection{New project investment}

After the accident, the plant developed comprehensive inspection and testing and decided to build a new boiler system. According to the calculation of the plant, the new project investment $\left(M_{\text {new }}\right)$ was about 200 million.

\subsection{Downstream production loss}

The products were mainly supplied to about 60 surrounding enterprises, as well as 6 enterprises accounted for about $80 \%$. Nearly all enterprises had to stop production. The downstream production loss $\left(M_{\mathrm{ds}}\right)$ was estimated by:

$$
\begin{array}{r}
M_{\mathrm{ds}}=\sum_{\mathrm{i}=1}^{60} M_{\mathrm{i}} \approx \frac{10}{8} \times \sum_{\mathrm{i}=1}^{6} M_{\mathrm{i}} \cdots \\
\left(M_{\mathrm{i}} \text { is single enterprise loss }\right)(6)
\end{array}
$$

The 6 main enterprises losses were listed as Table 1.

Table 1. The 6 main enterprises losses

\begin{tabular}{ccccc}
\hline Enterprise & $\begin{array}{c}\text { Annual turnover } \\
\text { (million) }\end{array}$ & $\begin{array}{c}\text { Influence level } \\
\text { (Steam stop) }\end{array}$ & Influence coefficient & $\begin{array}{c}\text { Production loss } \\
\text { (million) }\end{array}$ \\
\cline { 1 - 1 } Enterprise 1 & 8188 & Part & $20 \%$ & 327.5 \\
Enterprise 2 & 126 & All & $100 \%$ & 25.2 \\
Enterprise 3 & 242 & All & $100 \%$ & 48.4 \\
Enterprise 4 & 40 & All & $100 \%$ & 8 \\
Enterprise 5 & 20 & All & $100 \%$ & 4 \\
Enterprise 6 & 30 & All & $100 \%$ & 6 \\
& Downstream production loss $\boldsymbol{M}_{\mathrm{ds}}$ & & 523.9 \\
\hline
\end{tabular}

\subsection{Impact loss of workers in downstream enterprises}

The downstream enterprises were commonly small and scattered, as well as the employees were not stable. After the accident, many enterprises were unable to produce and in a state of production halt. Many workers decided to return to their hometowns or switch jobs. The loss was serious and it would take a long time and big effort to resume production.

After calculation, the annual steam supply was about 970 thousand tones, as well as the annual steam heat supply was about 2.7 million GJ. According to industry statistics. The work value per year of one in the industry of the local area was about 2.2 million.

Assuming half of the plant production was supplied to the industry, it was obtained that the accident affected about 3000 workers in the industry. Furthermore, assuming $10 \%$ of the workers resigned, and it takes an average of one month to re-recruit and train to work, the workers loss impact $\left(M_{\mathrm{wk}}\right)$ was estimated by:

$$
M_{\mathrm{wk}}=2.2 \times 3000 \times 10 \% \times \frac{1}{12}=55.7 \text { million (7) }
$$

\section{Conclusion}

According to the calculation, the total indirect economic losses of the example were about 669 million (include
$M_{\mathrm{sd}}, M_{\mathrm{wk}}, M_{\mathrm{ds}}$ and $\left.M_{\mathrm{wk}}\right)$. The $M_{\mathrm{dc}}$ and $M_{\text {new }}$ were seem as other effects that should not be included in economic losses. The ratio of indirect economic losses and direct economic losses is 35.4. It is much higher than the value 4 of general industrial accidents.

Furthermore, the steam in the accident pipe is nontoxic and harmless. Therefore, the cost of environmental damage and environmental cleanup has not been calculated. However, the internal medium of most special equipment has strong toxic and harmful effects. Once an accident occurs, it will cause serious environmental damage and environmental pollution. It can be predicted that the ratio value may be much higher.

In view of the extremely high ratio value of special equipment accidents, the safety of special equipment is particularly important. It is quite important to make concerted efforts to manufacture, usage, management, inspection, safety monitoring, and scientific supervision, in order to detect and eliminate hidden dangers early and ensure the safe operation of special equipment.

\section{Acknowledgments}

This work was financially supported by the science and technology project of Zhejiang Provincial Administration for Market Regulation (NO. 20190113). 


\section{References}

1. Yun Luo. (2013) Security Economics. China Quality Inspection Press, China Standard Press, Beijing.

2. Heinrich H W. (1959) Industrial Accident Prevention (fourth edition). McGraw Hill, New York.

3. Simonds, R H, Grimaldi, J V. (1963) Safety management: accident cost and control.

4. Andreoni D. (1985) The cost of occupational accidents and diseases.

5. HSE(OU). (1997) The Costs of Accidents at Work. HSE Books.

6. GB 6721-86. Statistical standard of economic losses from injury fatal accidents of enterprise staff and workers. 